University of Wollongong

Research Online

Australian Institute for Innovative Materials -

Papers

Australian Institute for Innovative Materials

$1-1-2014$

High performance pure sulfur honeycomb-like architectures synthesized by a cooperative self-assembly strategy for lithium sulfur batteries

Xin Liang

University of Wollongong, x|475@uowmail.edu.au

Mohammad Kaiser

University of Wollongong, mrk912@uowmail.edu.au

Konstantin Konstantinov

University of Wollongong, konstan@uow.edu.au

Richard Tandiono

PT Nipress Tbk, richard@nipress.com

Zhaoxiang Prof Zhaoxiang Wang

Chinese Academy Of Sciences

See next page for additional authors

Follow this and additional works at: https://ro.uow.edu.au/aiimpapers

Part of the Engineering Commons, and the Physical Sciences and Mathematics Commons

Research Online is the open access institutional repository for the University of Wollongong. For further information contact the UOW Library: research-pubs@uow.edu.au 


\title{
High performance pure sulfur honeycomb-like architectures synthesized by a cooperative self-assembly strategy for lithium sulfur batteries
}

\begin{abstract}
Honeycomb-like pure sulfur architectures were synthesized by a cooperative self-assembly strategy, in which a soft template is used to form the porous structure. Their electrochemical performance is significantly improved comparing with the commercial sulfur powder and the as-prepared sulfur without honeycomb morphology. There has been no report on using a soft template to prepare honeycomb-like sulfur particles.
\end{abstract}

\section{Keywords}

strategy, assembly, self, cooperative, synthesized, lithium, architectures, batteries, like, honeycomb, sulfur, pure, performance, high

Disciplines

Engineering | Physical Sciences and Mathematics

\section{Publication Details}

Liang, X., Kaiser, M., Konstantinov, K., Tandiono, R., Wang, Z., Liu, H., Dou, S. \& Wang, J. (2014). High performance pure sulfur honeycomb-like architectures synthesized by a cooperative self-assembly strategy for lithium sulfur batteries. RSC Advances: an international journal to further the chemical sciences, 4 (69), 36513-36516.

\section{Authors}

Xin Liang, Mohammad Kaiser, Konstantin Konstantinov, Richard Tandiono, Zhaoxiang Prof Zhaoxiang Wang, Hua-Kun Liu, S X. Dou, and Jiazhao Wang 
COMMUNICATIONS

\title{
High Performance Pure Sulfur Honeycomb-like Architectures Synthesized by Cooperative Self-assembly Strategy for the Lithium/Sulfur Battery
}

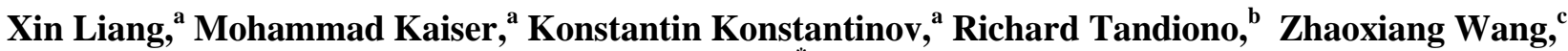 \\ ${ }_{5}$ Hua-Kun Liu, ${ }^{\text {a }}$ Shi-Xue Dou a and Jiazhao Wang, ${ }^{* a}$
}

Received (in $X X X, X X X)$ Xth $X X X X X X X X X 20 X X$, Accepted Xth XXXXXXXXX 20XX

DOI: 10.1039/b000000x

Honeycomb-like pure sulfur architectures were synthesized by a cooperative self-assembly strategy, in which a soft 10 template is used to form the porous structure. Their electrochemical performance is significantly improved comparing with the commercial sulfur powder and the asprepared sulfur without honeycomb morphology. There has been no report on using soft template to prepare honeycomb15 like sulfur particles.

Clean and efficient energy storage devices are in high demand due to the limited global energy supply, environmental pollution, and the increasing consumption of energy ${ }^{1,2}$. The rechargeable lithium/sulfur battery has attracted significant attention due to its 20 high theoretical specific capacity and power density ${ }^{3-8}$. Another advantage is that sulfur is abundant in nature, inexpensive and non-toxic ${ }^{9}$.

In spite of these considerable advantages, the fabrication of lithium/ sulfur batteries encounters a number of challenges. ${ }_{25}$ Sulfur is a highly electrically insulating material, which leads to poor electrochemical accessibility and low utilization of the sulfur in the electrode. The polysulfide anions which are formed as the reaction intermediates are highly soluble in the organic electrolyte solvent, which results in low active material 30 utilization, low coulombic efficiency, and short cycle life of the sulfur electrode ${ }^{10,11}$. In order to successfully operate the lithiumsulfur battery, the elemental sulfur must be well combined with a strong adsorbent to construct a composite cathode ${ }^{12-15}$, so as to reduce the diffusion of lithium polysulfides into the electrolyte ${ }^{16-}$ $35{ }^{19}$. The most promising adsorption agents for the Li/S battery are porous materials such as porous carbon ${ }^{4,12,15,20}$, with which porous structured sulfur-carbon composites are prepared by coating elemental sulfur on the surface of the porous carbon materials. The battery performance of these sulfur-carbon 40 composites has shown significant improvement over elemental sulfur, as the porous structure has the following positive effects towards improving the electrochemical performance ${ }^{21}$ : (1) the porous structure absorbs the soluble lithium polysulfides formed during discharge and reduces the dissolution of the active

45 materials into the electrolyte; (2) the porous structure increases the contact surface area between the sulfur and the carbon black, which increases the conductivity of the electrode; (3) the porous structure electrode has a faster charge transfer process, and thus the electrochemical kinetics of the porous sulfur - porous 50 additive electrode is improved in rechargeable lithium batteries. The previously reported methods used for preparation of sulfur porous additive composites are quite complicated, however, as well as being time-consuming, costly, not environmentally friendly, and difficult to scale up.

55
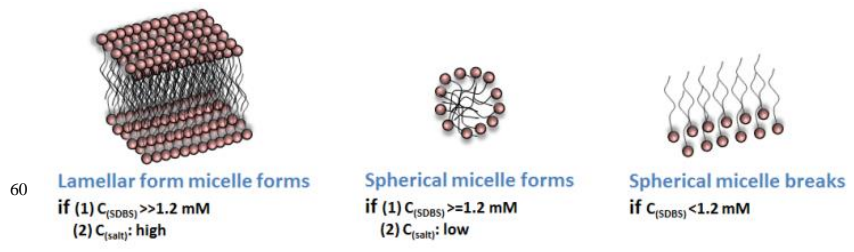

Figure 1. Different types of SDBS structure in aqueous solution.

It is therefore promising to try to synthesize pure sulfur with ${ }_{65}$ porous structure for $\mathrm{Li} / \mathrm{S}$ batteries. In this study, the sulfur particles with honeycomb morphology were prepared via a cooperative self-assembly process, while sodium dodecyl benzene sulphonate (SDBS) was used as a soft template to form the porous structure. This method is simple, easily scaled up, and 70 has low energy consumption, as shown in Figure S1 in the Supporting Information. SDBS is an excellent soft template to form porous structures ${ }^{22}$. As shown in Figure 1, the structure of SDBS in aqueous solution can easily take on different forms, responding to the concentration of SDBS $\left(\mathrm{C}_{\mathrm{SDBS}}\right)$ and the 75 concentration of salt $\left(\mathrm{C}_{\text {salt }}\right)$ in the solution ${ }^{22}$. When the concentration of SDBS is appropriate, SDBS prefers to form spherical micelles, which are essential to form a porous morphology, and this can be further confirmed by Table S2 and Figure S2. Moreover, SDBS is a non-toxic, biodegradable, and 80 environmentally friendly surfactant. In addition, SDBS is soluble and can be removed after the reaction by using distilled water. To the best of the authors' knowledge, there has been no report on using this method to prepare honeycomb-like sulfur particles. We believe that this method can provide useful guidance for 85 producing high surface area sulfur for various applications, such as in chemical fertilizers, the pharmaceutical industry, the rubber and fibre industries, bioleaching processes, anti-microbial agents, insecticides, fumigants, etc. ${ }^{23}$. 


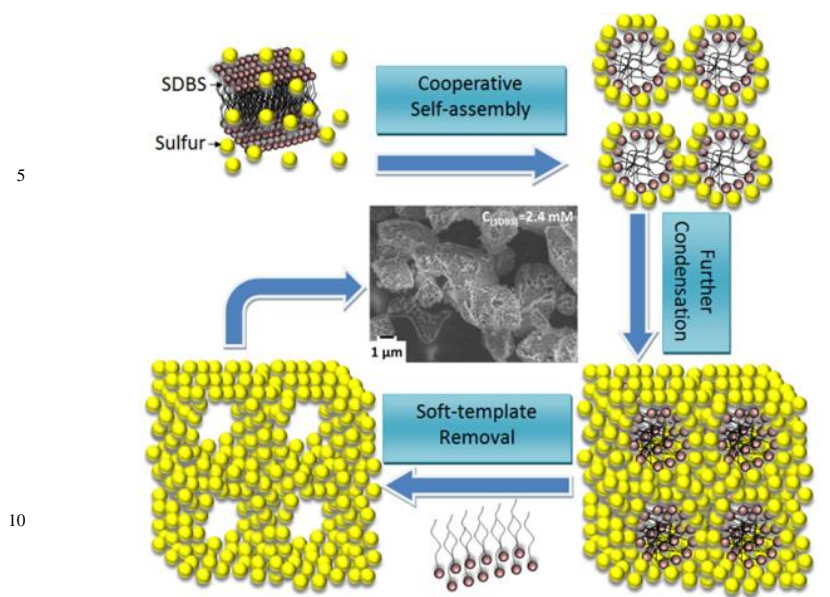

Figure 2. Mechanism of the synthesis of the honeycomb like sulfur particles.

The mechanism of the pore formation is shown in Figure 2. 15 First, after dropping $\mathrm{H}_{2} \mathrm{C}_{2} \mathrm{O}_{4}$ solution into $\mathrm{Na}_{2} \mathrm{~S}_{2} \mathrm{O}_{3}$ and SDBS solution, the SDBS lamellar micelles are transformed to spherical micelles as the concentrations of SDBS and salt decrease. At the same time, the sulfur starts to precipitate. Thus, cooperative selfassembly occurs between the sulfur and the SDBS spherical 20 micelles. Then, many more sulfur particles are produced, resulting in further condensation. Secondly, after adding a large amount of $\mathrm{H}_{2} \mathrm{O}$ into the above solution, the SDBS spherical micelles break, and the SDBS is removed. The sulfur particles with porous honeycomb-like structure are then finally obtained.

${ }_{25}$ Fig. 3(a) shows the XRD pattern of the prepared sulfur particles. The diffraction peaks can be indexed to the structure of space group Fddd (JCPDS No. 00-008-0247). Fig. 3(b) shows a field emission scanning electron microscope (FESEM) image of the as-prepared sulfur particles with SDBS. It is clear that the 30 morphology is a porous, honeycomb like structure. Fig. 3(c) shows that the sulfur particles without any pores are agglomerated when SDBS is absent. Thus, the SDBS is a critical factor for obtaining the porous sulfur particles. The comparative experiments with different starting concentrations of SDBS were 35 carried out, and it was found that the optimum starting concentration of SDBS was $2.4 \mathrm{mM}$ as shown in Table S1 and Fig. S2. The SEM image of the commercial sulfur powder in Fig. 3(d) shows that the commercial S particles have big particle size and smooth surfaces.

40 The Brunauer-Emmett-Teller (BET) tests have shown that the specific surface area of the commercial sulfur powder is 0.2023 $\mathrm{m}^{2} \mathrm{~g}^{-1}$, whereas the specific surface area of the as-prepared honeycomb-like sulfur is $1.0990 \mathrm{~m}^{2} \mathrm{~g}^{-1}$, which is about 5 times higher than that of the commercial sulfur powder.

45 The electrochemical performances of the honeycomb-like sulfur and the commercial sulfur particles were investigated. See the Supporting Information for details of the electrode and cell fabrication. Typical cyclic voltammograms (CV) of the porous sulfur electrode are shown in Fig. 4(a). In the first cycle, there are 50 two main reduction peaks at around 2.4 and $1.8 \mathrm{~V}$, and a small and broad peak near $2.1 \mathrm{~V}$ is also observed. The peak near $2.4 \mathrm{~V}$ corresponds to the reduction of elemental sulfur to higher-order lithium polysulfides $\left(\mathrm{Li}_{2} \mathrm{~S}_{\mathrm{n}}, \mathrm{n} \geqslant 8\right)$. The peak near $1.8 \mathrm{~V}$ can be assigned to the reduction from polysulfides to $\mathrm{Li}_{2} \mathrm{~S}$. The small 55 and broad peak near $2.1 \mathrm{~V}$ is related to the reduction of higherorder lithium polysulfides $\left(\mathrm{Li}_{2} \mathrm{~S}_{8}\right)$ to form lower-order lithium polysulfides, such as $\mathrm{Li}_{2} \mathrm{~S}_{6}$ and $\mathrm{Li}_{2} \mathrm{~S}_{4}{ }^{8}$, which are agreed well with the charge-discharge curve shown in Fig. S3. Compared to the first cycle, the reduction peaks in the following cycles are 60 shifted slightly to higher voltage because the electrochemical reaction during the first discharge process has to overcome the strong absorbing energy between the sulfur and the conductive matrix $^{24}$. From the second cycle, the intensity of the two oxidation peaks increases with cycling, which indicates that the ${ }_{65}$ lithium ion insertion/extraction into sulfur is an activated process $^{25}$. Fig. 4(b) shows the cycling performance of the honeycomb-like sulfur electrode. The potential range of 1.5-3.0 $\mathrm{V}$ was selected for the continuous charge-discharge cycling process. During the first 10 cycles, the specific discharge capacity 70 of the honeycomb-like sulfur electrode increased from 696.9 $\mathrm{mAh} \mathrm{g}^{-1}$ to $816.9 \mathrm{mAh} \mathrm{g}^{-1}$. These results are in good agreement with the $\mathrm{CV}$ measurements because of the activation process due to the gradual penetration of the electrolyte into the porous electrode. The discharge specific capacity slightly decreased after 7510 cycles. The cells retained a reversible discharge capacity higher than $650 \mathrm{mAh} \mathrm{g}^{-1}$ for 50 cycles, while the discharge capacity of the commercial sulfur is only about $200 \mathrm{mAh} \mathrm{g}^{-1}$. It is interesting that the discharge capacity of the initial cycle of the as-prepared sulfur $\left(\mathrm{C}_{(\mathrm{SDBS})}=0 \mathrm{mM}\right)$ electrode is as high as 1058 ${ }_{80} \mathrm{mAh} \mathrm{g}^{-1}$. It can be ascribed to the small particle size of the asprepared sulfur $\left(\mathrm{C}_{(\mathrm{SDBS})}=0 \mathrm{mM}\right)$ particles. The sulfur particle can be mixed very well with carbon black, thus the usage of the sulfur in the initial cycle is very high. But it is also very clearly that the capacity decay is dramatically due to the non-porous structure. ${ }_{85}$ The cell with the honey-comb like Sulfur electrode presents improved cycling stability due to the following reasons mentioned in the introduction in relation to the sulfur - porous carbon composite: reduction of the dissolution of the active materials into the electrolyte, increased conductivity of the 90 electrode, and improvement of the kinetics of the $\mathrm{Li}$ ion reaction with S.

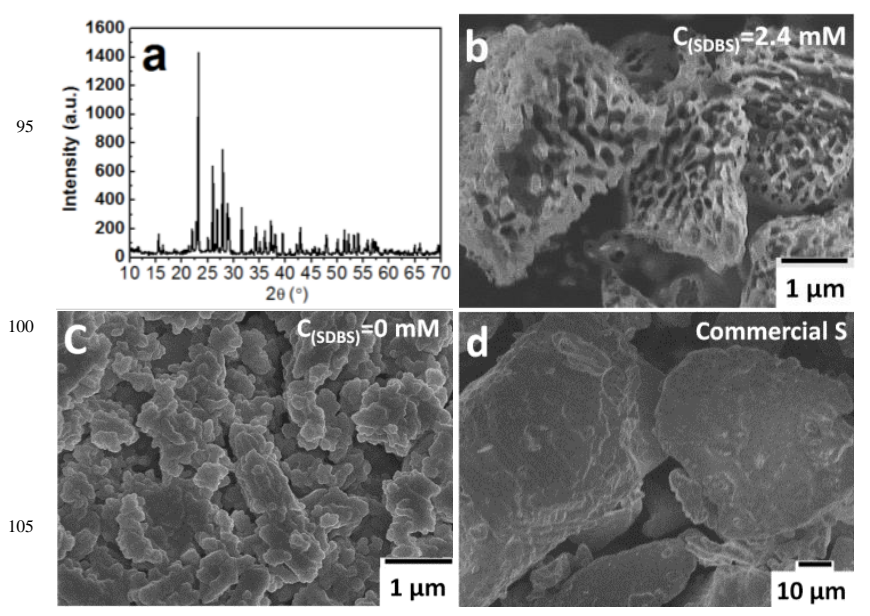

Figure 3. (a) XRD pattern of the sulphur particles; (b) FESEM image of as-prepared honeycomb-like sulfur made with SDBS at high magnification; (c) FESEM image of as-prepared sulfur particles without 110 SDBS; (d) FESEM image of commercial sulfur particles. 
In order to verify that the porous structure is responsible for the good performance of the $\mathrm{Li} / \mathrm{S}$ cell, electrochemical impedance spectroscopy (EIS) measurements were carried out on the commercial Sulfur, as-prepared Sulfur $\left(\mathrm{C}_{(\mathrm{SDBS})}=0 \mathrm{mM}\right)$ and 5 honeycomb-like Sulfur electrodes after 5 cycles (Fig. 4(c)). The cell containing honeycomb-like Sulfur shows smaller chargetransfer resistance than the cell with as-prepared Sulfur $\left(\mathrm{C}_{\text {(SDBS })}=0 \mathrm{mM}\right)$ electrode and especially the cell with commercial $\mathrm{S}$ electrode. Thus, the electrochemical kinetics of the honeycomb10 like sulfur has been improved in rechargeable lithium batteries. Figure 4 (d) shows the FESEM image of the honeycomb-like sulfur electrode after 50 cycles. It is clearly that the honeycomb morphology has maintained in the electrode film during cycling. A comparison of the rate capability between the honeycomb-like 15 sulfur electrode and the commercial sulfur electrode is shown in Figure S4. And the effect of the electrolyte has also been discussed in Figure S5.
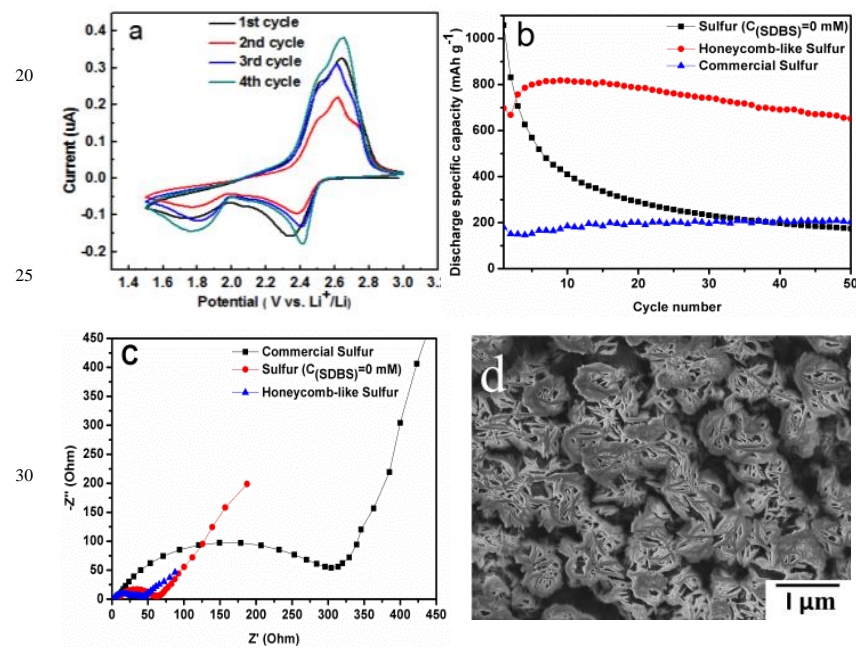

35 Figure 4. (a) Cyclic voltammograms for the first 4 cycles of the honeycomb-like sulfur electrode; (b) cycling performances of the honeycomb-like sulfur electrode, as-prepared sulfur $\left(\mathrm{C}_{(\mathrm{SDBS})}=0 \mathrm{mM}\right)$ electrode and the commercial sulfur electrode; (c) impedance plots for the honeycomb-like sulfur electrode, as-prepared sulfur $(\mathrm{C}(\mathrm{SDBS})=0 \mathrm{mM})$ 40 electrode and the commercial sulfur electrode; (d) FESEM image of the honeycomb-like sulfur electrode after 50 cycles

In summary, sulfur particles with honeycomb-like morphology were prepared via a cooperative self-assembly process. The batteries fabricated from the as-prepared honeycomb-like sulfur 45 cathode without any extra adsorption additives show significantly improved electrochemical performance compared with the batteries using commercial sulfur powder and even the asprepared sulfur without honeycomb-like morphology. The cells with the honeycomb-like sulfur electrode retained a reversible ${ }_{50}$ discharge capacity higher than $650 \mathrm{mAh} \mathrm{g}^{-1}$ for 50 cycles, while the discharge capacity of the commercial sulfur electrode was about $200 \mathrm{mAh} \mathrm{g}^{-1}$. Moreover, the honeycomb morphology is stable and can be maintained during cycling.

Financial support provided by an Australian Research ${ }_{55}$ Councial (ARC) Linkage Project (LP100100802) and industry partner PT Nipress TbK is gratefully acknowledged. Many thanks also go to Dr. Tania Silver for critical reading of the manuscript and valuable remarks. The first author also would like to thank the University of Wollongong as sponsor of the University ${ }_{60}$ Postgraduate Award and the International Postgraduate Tuition Award.

\section{Notes and references}

${ }^{a}$ Institute for Superconducting and Electronic Materials, University of Wollongong, NSW 2519, Australia. Fax: +61 24221 5731; Tel: +612 654298 1478; E-mail: jiazhao@uow.edu.au

${ }^{b}$ PT NIPRESS Tbk, J1.Raya Narogong KM. 26 Cileungsi, Bogor 16820 Indonesia

${ }^{c}$ Laboratory for Solid State Ionics, Institute of Physics, Chinese Academy of Sciences, PO Box 603, Beijing 100190, P. R. China

$70 \uparrow$ Electronic Supplementary Information (ESI) available: [experimental details, diagram of the synthesis process, table of parameters for comparative experiments, FESEM figures of the comparison experiment products,charge/discharge curve of Honeycomb-like sulfur cathode, a comparison of the rate capability between the honeycomb-like sulfur

75 electrode and the commercial sulfur electrode, rate capabilities of honeycomb-like sulfur electrode in different electrolyte]. See DOI: $10.1039 / \mathrm{b} 000000 \mathrm{x} /$

1. L. Wang, X. He, J. Li, J. Gao, J. Guo, C. Jiang and C. Wan, J. Mater. Chem., 2012, 22, 22077-22081.

80 2. Y. Deng, Z. Li, Z. Shi, H. Xu, F. Peng and G. Chen, RSC Adv., 2012, 2, 4645-4647.

3. L. Yin, J. Wang, X. Yu, C. W. Monroe, Y. NuLi and J. Yang, Chem. Commun., 2012, 48, 7868-7870.

4. X. L. Ji, K. T. Lee and L. F. Nazar, Nat. Mater., 2009, 8, 500-506.

85 5. H. L. Wang, Y. Yang, Y. Y. Liang, J. T. Robinson, Y. G. Li, A. Jackson, Y. Cui and H. J. Dai, Nano Lett., 2011, 11, 2644-2647.

6. J. Wang, J. Chen, K. Konstantinov, L. Zhao, S. H. Ng, G. X. Wang, Z. P. Guo and H. K. Liu, Electrochim. Acta, 2006, 51, 4634-4638.

7. N. W. Li, M. B. Zheng, H. L. Lu, Z. B. Hu, C. F. Shen, X. F. Chang,

90 G. B. Ji, J. M. Cao and Y. Shi, Chem. Commun., 2012, 48, 4106-4108.

8. L. W. Ji, M. M. Rao, H. M. Zheng, L. Zhang, Y. C. Li, W. H. Duan, J. H. Guo, E. J. Cairns and Y. G. Zhang, J. Am. Chem. Soc., 2011, 133, 18522-18525.

9. M.-S. Song, S.-C. Han, H.-S. Kim, J.-H. Kim, K.-T. Kim, Y.-M.

95 Kang, H.-J. Ahn, S. X. Dou and J.-Y. Lee, J. Electrochem. Soc., 2004, 151, A791-A795.

10. B. Zhang, X. Qin, G. R. Li and X. P. Gao, Energy Environ. Sci., 2010, 3, 1531-1537.

11. M. Nagao, A. Hayashi and M. Tatsumisago, Electrochim. Acta, 2011, $100 \quad \mathbf{5 6}, 6055-6059$.

12. J. Wang, S. Y. Chew, Z. W. Zhao, S. Ashraf, D. Wexler, J. Chen, S. H. Ng, S. L. Chou and H. K. Liu, Carbon, 2008, 46, 229-235.

13. X. Ji, K. T. Lee and L. F. Nazar, Nat Mater, 2009, 8, 500-506.

14. J.-Z. Wang, L. Lu, M. Choucair, J. A. Stride, X. Xu and H.-K. Liu, J. 105 Power Sources, 2011, 196, 7030-7034.

15. N. Jayaprakash, J. Shen, S. S. Moganty, A. Corona and L. A. Archer, Angew. Chem. Int. Ed., 2011, 123, 6026-6030.

16. X. L. Ji and L. F. Nazar, J. Mater. Chem., 2010, 20, 9821-9826.

17.Z. Wei Seh, W. Li, J. J. Cha, G. Zheng, Y. Yang, M. T. McDowell, P.110 C. Hsu and Y. Cui, Nat. Commun., 2013, 4, 1331-1331.

18. S. Evers, T. Yim and L. F. Nazar, J. Mater. Chem. C, 2012, 116, 19653-19658.

19. Y. J. Choi, B. S. Jung, D. J. Lee, J. H. Jeong, K. W. Kim, H. J. Ahn, K. K. Cho and H. B. Gu, Phys. Scr., 2007, T129, 62-65. 
20. C. Lai, X. P. Gao, B. Zhang, T. Y. Yan and Z. Zhou, J. Phys. Chem. C, 2009, 113, 4712-4716.

21. W. Yuan, D. Xie, Z. Dong, Q. Su, J. Zhang, G. Du and B. Xu, Mater. Lett., 2013, 97, 129-132.

5 22. N. Pal and A. Bhaumik, Adv.Colloid and Interface Sci., 2013, 189, $21-$

41.

23. Y. M. Guo, J. Z. Zhao, S. F. Yang, Z. C. Wang and H. B. Zhang, Powder Technol., 2006, 162, 83-86.

24. X. Liang, Z. Wen, Y. Liu, H. Zhang, J. Jin, M. Wu and X. Wu, J.

10 Power Sources, 2012, 206, 409-413.

25. X. Liang, Z. Wen, Y. Liu, H. Zhang, L. Huang and J. Jin, J. Power Sources, 2011, 196, 3655-3658. 


\section{High Performance Pure Sulfur Honeycomb-like Architectures Synthesized by Cooperative Self-assembly Strategy for the Lithium/Sulfur Battery}

Xin Liang, ${ }^{a}$ Mohammad Kaiser, ${ }^{a}$ Konstantin Konstantinov, ${ }^{a}$ Richard Tandiono, ${ }^{\text {b }}$ Zhaoxiang Wang, ${ }^{\mathrm{c}}$ Hua-Kun Liu, ${ }^{\mathrm{a}}$ Shi-Xue Dou ${ }^{\mathrm{a}}$ and Jiazhao Wang, ${ }^{{ }^{\mathrm{a}}}$

\footnotetext{
${ }^{a}$ Institute for Superconducting and Electronic Materials, University of Wollongong, NSW 2519, Australia. Fax: +61 $242215731 ;$ Tel: +61 24298 1478; E-mail: jiazhao@uow.edu.au

${ }^{b}$ PT NIPRESS Tbk, J1.Raya Narogong KM. 26 Cileungsi, Bogor 16820 Indonesia

${ }^{c}$ Laboratory for Solid State Ionics, Institute of Physics, Chinese Academy of Sciences, PO Box 603, Beijing 100190, P. R. China
}

\section{Electronic Supplementary Information (ESI)}




\section{Experimental details:}

\section{Materials:}

Sodium thiosulphate $\left(\mathrm{Na}_{2} \mathrm{~S}_{2} \mathrm{O}_{3}\right)$, oxalic acid $\left(\mathrm{H}_{2} \mathrm{C}_{2} \mathrm{O}_{4}\right)$, sulfur $(\mathrm{S})$, and SDBS were all purchased from Sigma Aldrich (Australia). All the chemicals were used as received without any further purification.

\section{Preparation of honeycomb-like sulfur:}

Firstly, $3.60 \mathrm{~g} \mathrm{H}_{2} \mathrm{C}_{2} \mathrm{O}_{4}$ was dissolved in $250 \mathrm{~mL}$ distilled water at room temperature under vigorous stirring. Subsequently, $3.16 \mathrm{~g} \mathrm{Na}_{2} \mathrm{~S}_{2} \mathrm{O}_{3}$ was also dissolved in $250 \mathrm{~mL}$ distilled water, and then $0.21 \mathrm{~g}$ SDBS was added and stirred vigorously. Afterwards, the $\mathrm{H}_{2} \mathrm{C}_{2} \mathrm{O}_{4}$ solution was dropped into the $\mathrm{Na}_{2} \mathrm{~S}_{2} \mathrm{O}_{3}$ and SDBS solution within 20 minutes. After that, 30 minutes were allowed for the completion of the reaction under vigorous stirring. Then, over $500 \mathrm{~mL}$ distilled water was added into the solution. A light yellow powder was obtained after centrifuging. The light yellow powder was then dried in a vacuum oven at $45^{\circ} \mathrm{C}$ for 24 hours after washing several times with distilled water and acetone. For comparison, sulfur particles without pores were prepared following a similar procedure in the absence of SDBS.

\section{Physical Characterization:}

The structure of the sulfur particles was characterized by X-ray diffraction (XRD) using a GBC MMA X-ray generator and diffractometer with $\mathrm{Cu} \operatorname{K\alpha }$ radiation $(\lambda=1.5418 \AA)$, employing a scanning rate of $5^{\circ} / \mathrm{min}$ in the $2 \theta$ range from $10^{\circ}$ to $70^{\circ}$. The morphology of the sulfur powder was investigated by field emission scanning electron microscope (FE-SEM; JEOL JSM-7500FA). The specific surface area of the powders was examined by gas sorption analysis using the Brunayer- Emmett-Teller method (Quanta Chrome Nova 1000).

\section{Electrochemical measurements:}

The working electrodes were prepared by mixing $50 \mathrm{wt}$. \% as-synthesized sulfur powder with 40 wt. \% carbon black and 10 wt. \% polyvinylidene fluoride (PVDF) binder in 
N-methyl-2-pyrrolidinone (NMP) solvent. The well-mixed slurry was tape-cast onto a sheet of aluminium foil substrates. The commercial sulfur was treated in the same way for comparison. The coated electrodes were dried in a vacuum oven at $45{ }^{\circ} \mathrm{C}$ for $48 \mathrm{~h}$ and then pressed. Subsequently, the electrodes were cut to a $1 \times 1 \mathrm{~cm}^{2}$ size. The loading weight of the active material is around $1 \mathrm{mg} / \mathrm{cm}^{2} .1 \mathrm{M}$ lithium bistrifluoromethanesulfonamide (LiTFSI) in poly (ethylene glycol) dimethyl ether 500 (PEGDME 500) was used as electrolyte. $0.1 \mathrm{M}$ $\mathrm{LiNO}_{3}$ salt was used as an electrolyte additive. To compare the effect of the electrolyte, another electrolyte was also prepared, which is 1 mol/L lithium bistrifluoromethanesulfonamide (LiTFSI) in 1,3-Dioxolane(DOL) / 1,2-Dimethoxyethane (DME) ( $1: 1$ by volume) with $0.1 \mathrm{~mol} \mathrm{L-1} \mathrm{LiNO}_{3}$ as an additive. CR2032 coin cells were assembled in an Ar-filled glove box. Charge-discharge testing was carried out with a LAND battery test system at a current density of $50 \mathrm{~mA} \mathrm{~g}^{-1}$ with a voltage range of $1.5-3.0 \mathrm{~V}$. Cyclic voltammetry $(\mathrm{CV})$ and $\mathrm{AC}$ impedance measurements were performed using a Biologic VMP3 Multichannel electrochemistry workstation at a scanning rate of $0.1 \mathrm{mV} \mathrm{s}^{-1}$ and a frequency range of $100 \mathrm{KHz}-0.01 \mathrm{~Hz}$, respectively. 


\section{Supplemental Table and Figures}

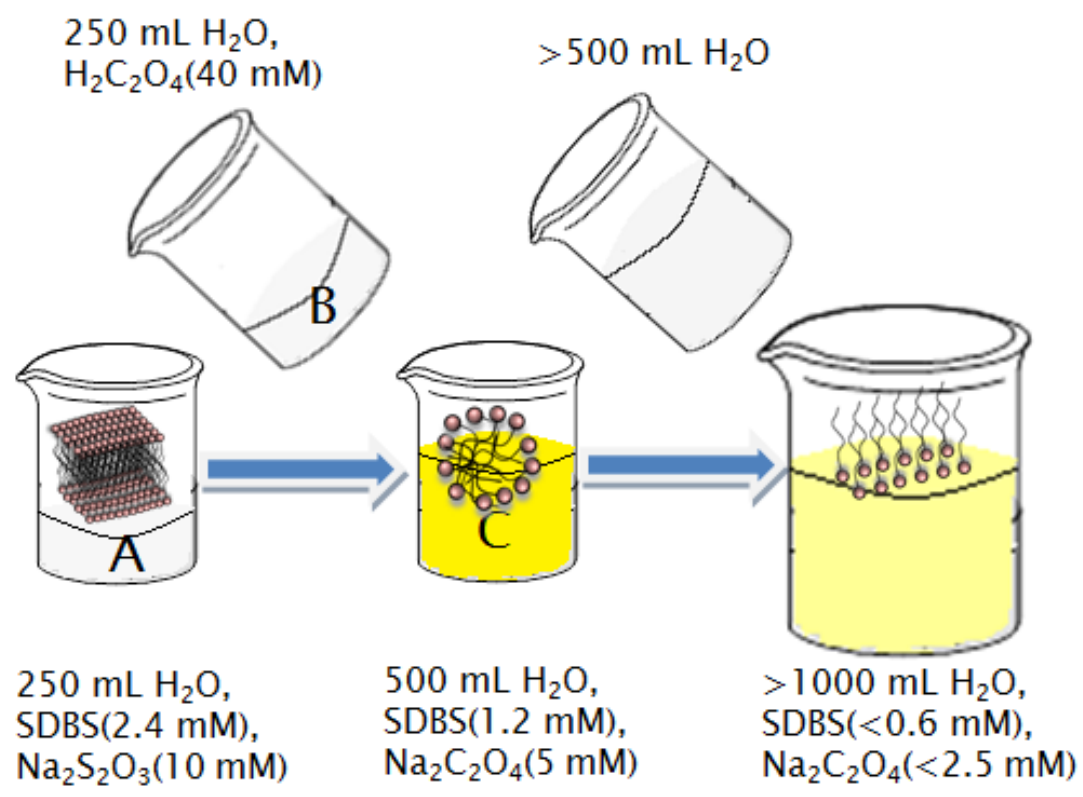

Figure S1. Details of the synthesis.

Figure S1 shows the details of the synthesis. Solution A is $250 \mathrm{~mL}$ aqueous solution with $2.4 \mathrm{mM}$ SDBS and $10 \mathrm{mM} \mathrm{Na}_{2} \mathrm{~S}_{2} \mathrm{O}_{3}$, while solution $\mathrm{B}$ is $250 \mathrm{~mL}$ distilled water with $40 \mathrm{mM}$ $\mathrm{H}_{2} \mathrm{C}_{2} \mathrm{O}_{4}$. In solution $\mathrm{A}$, the concentration of SDBS is much higher than $1.2 \mathrm{mM}$, and the concentration of salt $\left(\mathrm{Na}_{2} \mathrm{~S}_{2} \mathrm{O}_{3}\right)$ is also quite high, thus the SDBS prefers to form lamellar micelles. After dropping solution B into solution A, solution C was produced, which is 500 $\mathrm{mL}$ distilled water with $1.2 \mathrm{mM}$ SDBS and $5 \mathrm{mM} \mathrm{Na}_{2} \mathrm{~S}_{2} \mathrm{O}_{3}$. As both the concentrations of SDBS and salt decrease, the SDBS lamellar micelles were transformed to spherical micelles which will form when the concentration of SDBS is equal or only a little bit higher than 1.2 $\mathrm{mM}$ and the concentration of salt $\left(\mathrm{Na}_{2} \mathrm{~S}_{2} \mathrm{O}_{3}\right)$ is low. At the same time, the sulfur starts to precipitate. Thus, cooperative self-assembly occurs between the sulfur and the SDBS spherical micelles. Then, many more sulfur particles are produced, resulting in further condensation. Secondly, after adding a large amount of $\mathrm{H}_{2} \mathrm{O}$ into solution $\mathrm{C}$, the SDBS spherical micelles break because of the low concentration of SDBS and salt, and then the SDBS is removed. Finally, the sulfur particles with porous honeycomb-like structure are 
obtained.

Table S1 Parameters of the comparative experiments.

\section{Conditions}

(Figures in Fig.S2)
Starting concentration of

SDBS in solution A

\section{Final concentration of SDBS}

in solution $\mathbf{C}$

\begin{tabular}{lcc}
\hline $\mathbf{1}$ (Fig. S2a) & $4.8 \mathrm{mM}$ & $2.4 \mathrm{mM}$ \\
$\mathbf{2}$ (Fig. S2b) & $2.4 \mathrm{mM}$ & $1.2 \mathrm{mM}$ \\
3 (Fig. S2c) & $1.2 \mathrm{mM}$ & $0.6 \mathrm{mM}$ \\
$\mathbf{4}$ (Fig. S2d) & $0.6 \mathrm{mM}$ & $0.3 \mathrm{mM}$ \\
\hline
\end{tabular}

The comparative experiments with different starting concentrations of SDBS were carried out. As shown in table S1, there are four different starting concentrations of SDBS were applied, $4.8 \mathrm{mM}, 2.4 \mathrm{mM}, 1.2 \mathrm{mM}$ and $0.6 \mathrm{mM}$ respectively. After adding $250 \mathrm{~mL} 40$ $\mathrm{mM} \mathrm{H} \mathrm{H}_{2} \mathrm{O}_{4}$ solution (solution $\mathrm{B}$ ) into solution $\mathrm{A}$, the concentrations of SDBS in solution $\mathrm{C}$ have reduced to $2.4 \mathrm{mM}, 1.2 \mathrm{mM}, 0.6 \mathrm{mM}, 0.3 \mathrm{mM}$ respectively. 


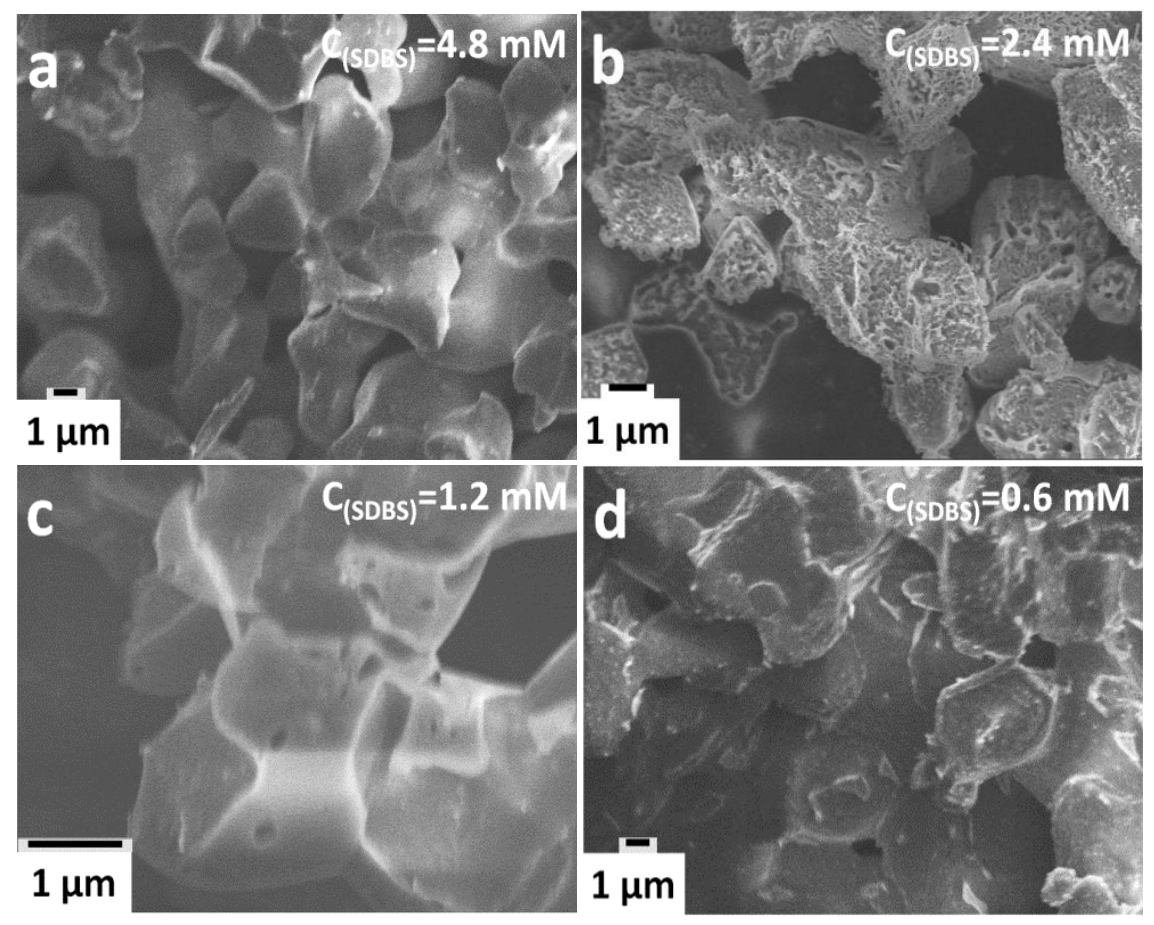

Figure S2. FESEM images of the as-prepared sulfur with different starting concentrations of SDBS: (a) $4.8 \mathrm{mM}$, (b) $2.4 \mathrm{mM}$, (c) $1.2 \mathrm{mM}$, (d) $0.6 \mathrm{mM}$.

Fig. S2 presents the relative FESEM images of the obtained sulfur particles in the comparison experiments. It is shown in Fig. S2a that there is not any porous structure of the sulfur particles can be observed when the start concentration of the SDBS is $4.8 \mathrm{mM}$. Because after adding solution B into solution A, the concentration of SDBS reduced to 2.4 $\mathrm{mM}$, thus during all the reaction, the concentration of SDBS is much higher than $1.2 \mathrm{mM}$, which is the critical micelle concentration of SDBS to form spherical micelles. The second condition was using $2.4 \mathrm{mM}$ as the starting concentration of SDBS, after dropping solution B into solution $\mathrm{A}$, the concentration of SDBS decreased to $1.2 \mathrm{mM}$, and has been kept for 30 mins. Thus, the cooperative self-assembly occurs between the sulfur and the SDBS spherical micelles. Fig S2b shows that honeycomb-like porous sulfur was obtained. In condition 3, the starting concentration of SDBS is $1.2 \mathrm{mM}$, so in solution A SDBS exists as spherical micelles, thus, a little amount precipitated sulfur can cooperative self-assemble with the 
spherical SDBS micelles at the very beginning of the reaction after adding solution B. That's why there some pores have been observed in Fig.S2c. In the fourth condition, 0.6mM was used as the starting concentration of SDBS, after the reaction, the final concentration of SDBS is only $0.3 \mathrm{mM}$, the concentration of SDBS is much lower than the critical micelle concentration of $\operatorname{SDBS}(1.2 \mathrm{mM})$. thus there is no spherical micelles exist during all the reaction progress, therefore the FESEM images of the obtained sulfur in Fig S2d shows no pores either. Based on the discussion above, it was found that the optimum starting concentration of SDBS was $2.4 \mathrm{mM}$. 


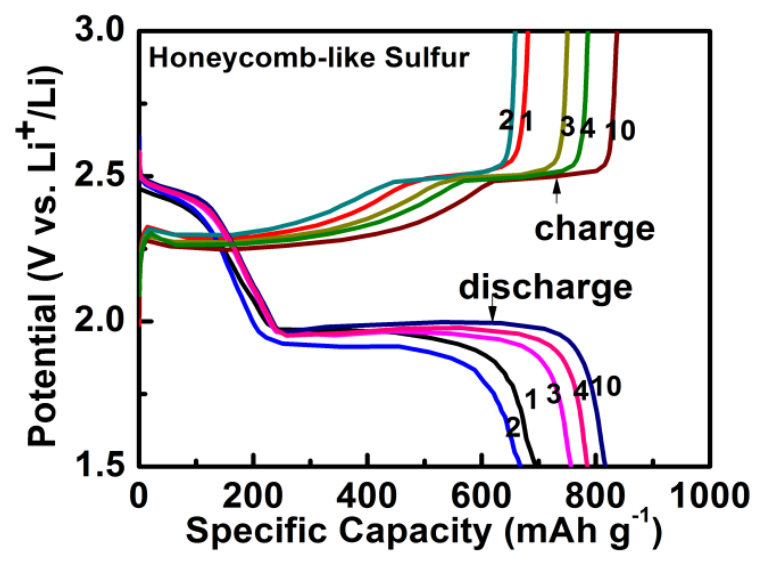

Figure S3. The charge/discharge profiles of the selected cycles of the honeycomb-like cathode.

The charge-discharge profiles in Fig. S4 are assigned to the two-step reaction of sulfur with lithium, a typical process in $\mathrm{Li} / \mathrm{S}$ batteries. The charge and discharge potential values of the upper and lower plateaus are stabilized at approximately 2.5 and $2.27 \mathrm{~V}$, and 2.44 and $1.97 \mathrm{~V}$, respectively. 


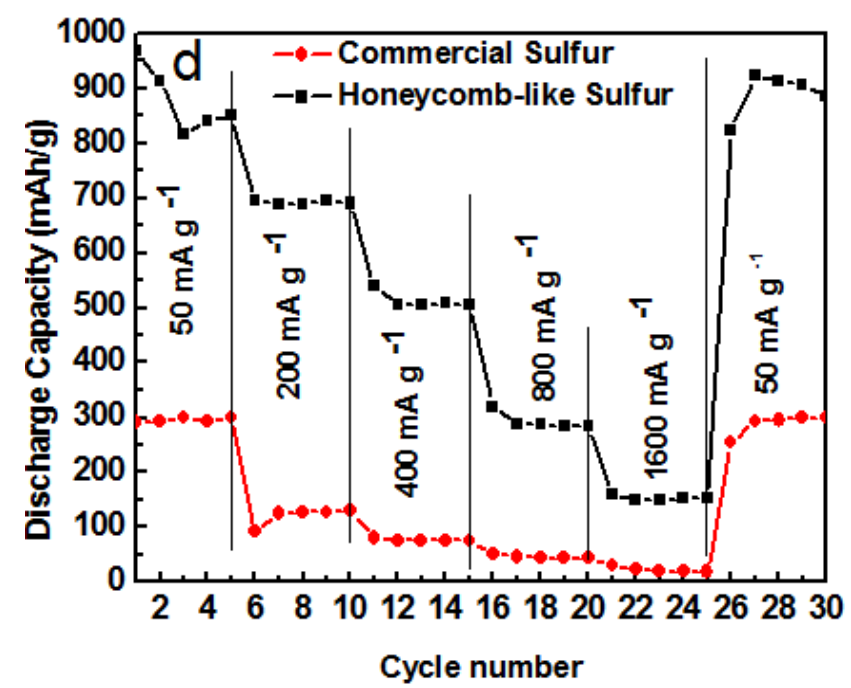

Figure S4. The rate capabilities of the honeycomb-like sulfur electrode and the commercial sulfur electrode

A comparison of the rate capability between the honeycomb-like sulfur electrode and the commercial sulfur electrode is shown in Fig. S4. The discharge capacity of the honeycomblike sulfur electrode decreases gradually as the current density is increased from 50 to 1600 $\mathrm{mA} \mathrm{g}^{-1}$, and then it recovers most of its original capacity when the current density is reduced back to $50 \mathrm{~mA} \mathrm{~g}^{-1}$. After 25 cycles, its discharge capability can still reach $900 \mathrm{mAh} \mathrm{g}^{-1}$. In contrast, the rate capability of the commercial sulfur electrode is very bad. When the current density rises to $1600 \mathrm{~mA} \mathrm{~g}^{-1}$, the retained discharge capacity of the commercial sulfur electrode is only about $20 \mathrm{mAh} \mathrm{g}^{-1}$. 


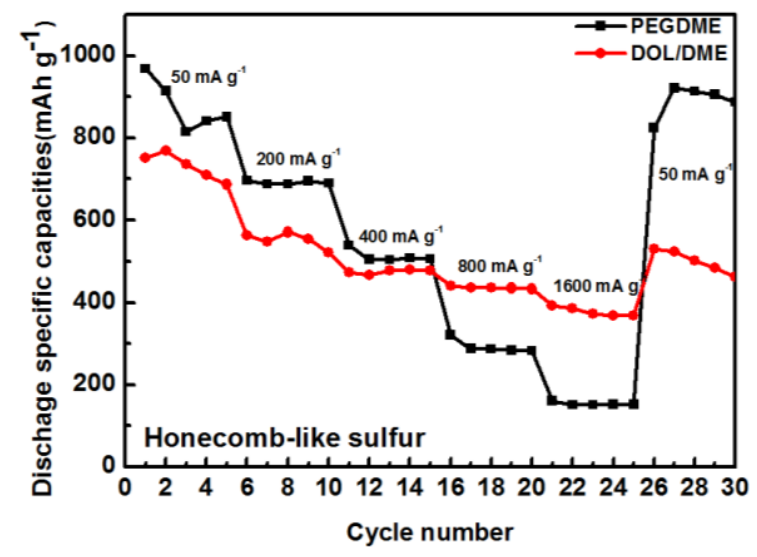

Figure S5. The rate capabilities of honeycomb-like sulfur electrode in PEGDME 500 and DOL/DME(1/1).

It is well known that compare to PEGDME 500 solvent, 1,3-dioxolane (DOL) and 1,2-dimethoxyethane (DME) have good ionic conductivity and low viscosity which is essential to enhance the high rate capabilities[1,2]. Thereby, in order to optimize the high rate behaviour of the honeycomb-like sulfur cathode, $1 \mathrm{~mol} / \mathrm{L}$ lithium bistrifluoromethanesulfonamide (LiTFSI) in a mixed solvent of 1,3-Dioxolane(DOL) / 1,2Dimethoxyethane (DME) (1: 1 by volume) with $0.1 \mathrm{~mol} \mathrm{~L}^{-1} \mathrm{LiNO}_{3}$ as an additive was used as electrolyte to test the rate capabilities of the honeycomb-like sulfur cathode as well. As shown in Figure S5, when the current densities are lower than $400 \mathrm{~mA} \mathrm{~g}^{-1}$, the honeycomblike sulfur cathode in the electrolyte with a mixed solvent of 1,3-Dioxolane(DOL)/1,2Dimethoxyethane (DME) (1: 1 by volume) shows lower capacities than in the electrolyte with solvent of PEGDME due to high solubility of polysulfides in DOL/DME. But when current densities are higher than $400 \mathrm{~mA} \mathrm{~g}^{-1}$, the honeycomb-like sulfur cathode in the electrolyte with a mixed solvent of 1,3-Dioxolane(DOL)/1,2-Dimethoxyethane (DME) $(1: 1$ by volume) presents much higher capacities than in the electrolyte with solvent of PEGDME. In addition, when the current density is increasing, the improvement becomes much obvious. Specifically, the capacities has been improved $140 \mathrm{mAh} \mathrm{g}^{-1}$ at $800 \mathrm{~mA} \mathrm{~g}^{-1}$ and $250 \mathrm{mAh} \mathrm{g}^{-1}$ at $1600 \mathrm{~mA} \mathrm{~g}^{-1}$. It further confirmed that the high-rate performance depends on the ion diffusion speed and the electronic conductivity of the electrolyte solvent.

[1] Y. Yang, G. Zheng, Y. Cui, Chem. Soc. Rev., 42 (2013) 3018-3032.

[2] G. He, X. Ji, L. Nazar, Energy Environ. Sci., 4 (2011) 2878-2883. 